\title{
Awareness about cervical cancers among health workers in Shimla district, Himachal Pradesh, India
}

\author{
Vikas Fotedar $^{1 *}$, Shailee Fotedar ${ }^{2}$, Purnima Thakur ${ }^{1}$, Mukesh Sharma ${ }^{1}$, Aman Sharma ${ }^{1}$
}

\author{
${ }^{1}$ Department of Radiation Oncology, Regional cancer Center, Indira Gandhi Medical College, Shimla, Himachal \\ Pradesh, India \\ ${ }^{2}$ Department of Public Health Dentistry, HP Government Dental College, Shimla, Himachal Pradesh, India
}

Received: 19 July 2017

Accepted: 18 August 2017

\section{*Correspondence:}

Dr. Vikas Fotedar,

E-mail: drfotedar@rediffmail.com

Copyright: (c) the author(s), publisher and licensee Medip Academy. This is an open-access article distributed under the terms of the Creative Commons Attribution Non-Commercial License, which permits unrestricted non-commercial use, distribution, and reproduction in any medium, provided the original work is properly cited.

\begin{abstract}
Background: Cervical cancer, although largely preventable, remains the most common cause of cancer mortality among women in low-resource countries. Aim of this study was to assess knowledge and awareness of cervical cancer prevention among health workers in Shimla district, Himachal Pradesh.

Methods: A cross sectional study was conducted among multipurpose health care workers (both males and females) in Shimla district, Himachal Pradesh. A self-administered close ended questionnaire was used. The questionnaire, consisted of two parts. The first part comprised of questions relating to demographic data and the second part had questions on knowledge about cervical cancers. The data was analyzed using the statistical analysis program SPSS version 16.0. Tests used were Chi square, $\mathrm{t}$ test and ANOVA. A p-values $<0.05$ were considered statistically significant.

Results: Out of 122 subjects, there were 45 (36.9\%) males and 77 (63.1\%) females. The mean knowledge percent of the population was 55.9+16.4. Among the age groups it was highest for the age group of 21-30 years $(62.5+23.6)$ and lowest for the age group of 51-60 years $(53.6+16.4)$. Knowledge about risk factors was correctly reported by $44.3 \%$ of population. Who should be screened for cervical cancers was reported correctly by $29.5 \%$ and at what interval screening should be done was reported by $14.8 \%$.

Conclusions: Half of the population had moderate overall knowledge about cervical cancers, but the knowledge about risk factors and screening eligibility and screening interval was inadequate. So, education programs should be arranged for the health workers in order to prevent cervical cancers.
\end{abstract}

Keywords: Cervical cancer, Health worker and knowledge

\section{INTRODUCTION}

Cervical cancer is the second leading cancer among women worldwide after breast cancer. Every year,500 000 new cases are diagnosed and 270000 women die of this disease. ${ }^{1}$ The world pattern of cervical cancer indicates that this is predominantly a problem of developing countries. India shares a staggering one fifth of this global burden, with one out of every five women in the world suffering from cervical cancer being an Indian. ${ }^{2}$ In the state of Himachal Pradesh, cancer cervix is a major public health problem since it ranks as the number one female cancer as per the annual reports of Regional Cancer Center, Himachal Pradesh for the last 10 years. ${ }^{3}$

Cervical cancer has a long premalignant period that provides the opportunity to screen and treat before it 
becomes invasive cervical cancer. ${ }^{4}$ Along with this, it is largely preventable by effective screening programs and considerable reduction in cervical cancer incidence and deaths has been achieved with systematic cytological smear screening programs.,6 Primary prevention of cervical cancer aims at reducing the incidence of cervical cancer by controlling the causes as well as risk factors.

As per the national cancer control program, guidelines for cervical screening program, the backbone of the health system is the cadre of health workers, both male and female. They are also known as multi-purpose workers. The health workers pay home visits, maintain the family records and provide promotive and preventive services. The Medical Officer, Public Health Nurse, Health Assistant, and Health Workers will have to take a lead in the screening programme of cervical cancers. So, the multipurpose workers being the gross root workers are also accountable for prevention of cervical cancers. ${ }^{2}$

For effective education and communication by the multipurpose health workers, they need to have good knowledge about cervical cancers. To assure that they acquire appropriate knowledge and practices about cervical cancers, it is important to assess their existing knowledge and practices about cervical cancers. To our knowledge no such study has been conducted in this state, the present study was conducted to assess the knowledge and practices among multipurpose health care workers in Shimla district.

\section{METHODS}

A cross sectional study was conducted among multipurpose health care workers (both males and females) in Shimla district, Himachal Pradesh. Prior permission was taken from the Chief Medical Officer, Shimla district to conduct the study.

For administrative purposes, Shimla district is divided into nine developmental blocks, namely Mashobra, Rampur, Jubbal, Rohru, Theog, Chopal, Basantpur, Nankhari and Chuara. ${ }^{7}$ Four blocks namely Mashobra, Rampur, Mathiana and Nankhari were selected randomly to conduct the study.

All the health workers working in the sub centers, PHC's, CHC's and Civil hospitals in these blocks were invited to participate in the study. Those health personnel who were willing to participate and who gave informed consent were included in the study. A total of 142 questionnaires were distributed. Out of 142 , we received back 129 questionnaires. Out of 129 , seven were incomplete and were excluded and thus making a total of 122 as a study population.

A self-administered close ended questionnaire was used. The questionnaire, which was used in the study, consisted of two parts. The first part comprised of questions relating to demographic data including age, gender, education, marital status and place of posting. The second part had ten questions on knowledge about cervical cancers such as risk factors, symptoms and screening procedures, and two questions on their attitude. For calculating mean knowledge, each correct answer was given a score of 1 and 0 for each incorrect answer. These scores were transformed into percentages of correct answers.

Hence, a subjects' total score could range from 0 (no answers correct) to 100 percent (all twelve answers correct). Subjects with a score less than 30 percent were considered to have weak knowledge, between 30 and 60 percent to have moderate knowledge, and between 60 and 100 percent to have good knowledge.

\section{RESULTS}

Out of 122 subjects, there were $45(36.9 \%)$ males and 77 $(63.1 \%)$ females. The mean age of the population was $48.6+5.6$ with a range of 25 to 59 . In the present population, $92(75.4 \%)$ were in the age group of $45-54$ years followed by $15(12.3 \%)$ in the age group of $35-44$ yrs.

Most of the participants $66(54.1 \%)$ had a qualification of matriculation followed by 12 th pass $28(23 \%)$. Half of the population $60(49.2 \%)$ had almost $21-30$ years of service (Table 1).

Table 1: Demographic profile of the subjects.

\begin{tabular}{|lll|}
\hline Variable & N & n $(\%)$ \\
\hline Gender & & \\
\hline Male & 45 & 36.9 \\
\hline Female & 77 & 63.1 \\
\hline Marital status & & \\
\hline Married & 118 & 96.7 \\
\hline Unmarried & 4 & 3.3 \\
\hline Age groups (years) & & \\
\hline $21-30$ & 4 & 3.3 \\
\hline $31-40$ & 15 & 12.3 \\
\hline $41-50$ & 92 & 75.4 \\
\hline $51-60$ & 11 & 9.0 \\
\hline Level of education & & \\
\hline $10^{\text {th }}$ pass & 66 & 54.1 \\
\hline $12^{\text {th }}$ pass & 28 & 23.0 \\
\hline Graduation & 23 & 18.9 \\
\hline Post graduation & 05 & 4.1 \\
\hline Years in job & & \\
\hline $1-10$ & 3 & 2.5 \\
\hline $11-20$ & 49 & 40.2 \\
\hline $21-30$ & 60 & 49.2 \\
\hline 31.40 & 10 & 8.2 \\
\hline
\end{tabular}

The mean knowledge percent of the population was $55.9+16.4$. The mean knowledge was higher for females $(56.1+16.9)$ than males $(55.5+15.6)$. 
Among the age groups it was highest for the age group of 21-30 years $(62.5+23.6)$ and lowest for the age group of 51-60 years $(53.6+16.4)$. The mean knowledge was highest for those who had a qualification of graduation (Table 2).

Table 2: Mean knowledge according to gender, age and level of education.

\begin{tabular}{|c|c|c|c|}
\hline Variable & $\mathbf{N}$ & $\begin{array}{l}\text { Mean knowledge } \\
\text { percent }\end{array}$ & p value \\
\hline \multicolumn{4}{|l|}{ Gender } \\
\hline Male & 45 & $55.5 \pm 15.6$ & \multirow{2}{*}{0.43} \\
\hline Female & 77 & $56.1 \pm 16.9$ & \\
\hline \multicolumn{4}{|c|}{ Age groups (years) } \\
\hline $21-30$ & 4 & $62.5 \pm 23.6$ & \multirow{4}{*}{0.58} \\
\hline $31-40$ & 15 & $60.0 \pm 11.3$ & \\
\hline $41-50$ & 92 & $55.2 \pm 15.2$ & \\
\hline $51-60$ & 11 & $53.6+16.4$ & \\
\hline \multicolumn{4}{|c|}{ Level of education } \\
\hline $10^{\text {th }}$ pass & 66 & $58.1+15.1$ & \multirow{4}{*}{0.08} \\
\hline $12^{\text {th }}$ pass & 28 & $49.2+18.0$ & \\
\hline Graduation & 23 & $58.2+15.2$ & \\
\hline $\begin{array}{l}\text { Post } \\
\text { graduation }\end{array}$ & 05 & $52.0+21.6$ & \\
\hline
\end{tabular}

Approximately $53.3 \%$ of the population had moderate knowledge followed by good knowledge in $35.2 \%$ followed by poor knowledge in $11.5 \%$ of the population (Table 3).

Table 3: Knowledge levels of the population.

\begin{tabular}{|c|c|c|c|c|}
\hline \multirow{2}{*}{$\begin{array}{l}\text { Level of } \\
\text { knowledge }\end{array}$} & \multicolumn{2}{|l|}{ Gender } & \multirow{2}{*}{ Total } & \multirow{2}{*}{$\begin{array}{l}\mathbf{P} \\
\text { value }\end{array}$} \\
\hline & Male & Female & & \\
\hline Poor & $\begin{array}{l}4 \\
(8.8 \%)\end{array}$ & $\begin{array}{l}10 \\
(12.9 \%)\end{array}$ & $\begin{array}{l}14 \\
(11.5 \%)\end{array}$ & \multirow{4}{*}{0.50} \\
\hline Moderate & $\begin{array}{l}27 \\
(60.0 \%)\end{array}$ & $\begin{array}{l}38 \\
(49.3 \%)\end{array}$ & $\begin{array}{l}65 \\
(53.3 \%)\end{array}$ & \\
\hline Good & $\begin{array}{l}14 \\
(31.2 \%)\end{array}$ & $\begin{array}{l}29 \\
(37.6 \%)\end{array}$ & $\begin{array}{l}43 \\
(35.2 \%)\end{array}$ & \\
\hline Total & $\begin{array}{l}45 \\
(100 \%)\end{array}$ & $\begin{array}{l}77 \\
(100 \%)\end{array}$ & $\begin{array}{l}122 \\
(100 \%)\end{array}$ & \\
\hline
\end{tabular}

Cervical cancer is most common cancers in females in India was reported correctly by $75 \%$ of the subjects. Knowledge about risk factors was correctly reported by $44.3 \%$ of population.

Question on who should be screened for cervical cancers was reported correctly by $29.5 \%$ and at what interval screening should be done was reported by $14.8 \%$ of the population (Table 4).

Cervical cancer screening is an essential part of women's health care was reported by $98 \%$ of population and $68 \%$ said it should be started in the community.
Table 4: Correct responses to questions on knowledge about cervical cancers.

\begin{tabular}{|c|c|c|}
\hline S. no & Statements & $\begin{array}{l}\text { Correct } \\
\text { response } \\
\text { No }(\%)\end{array}$ \\
\hline 1. & $\begin{array}{l}\text { Cervical cancer is most common } \\
\text { cancers in females in India }\end{array}$ & $92(75.4 \%)$ \\
\hline 2. & $\begin{array}{l}\text { Risk factors for cancer of cervix } \\
\text { include }\end{array}$ & $54(44.3 \%)$ \\
\hline 3. & Cervical cancer presents as & $64(52.5 \%)$ \\
\hline 4. & $\begin{array}{l}\text { Pap test is used for detection of } \\
\text { cervical cancer. }\end{array}$ & $111(91 \%)$ \\
\hline 5. & $\begin{array}{l}\text { Pap test can detect precancerous } \\
\text { lesions. }\end{array}$ & $\begin{array}{l}103 \\
(84.4 \%)\end{array}$ \\
\hline 6. & $\begin{array}{l}\text { Early cervical changes are easily } \\
\text { curable. }\end{array}$ & $\begin{array}{l}116 \\
(95.1 \%)\end{array}$ \\
\hline 7. & $\begin{array}{l}\text { Who should be screened for } \\
\text { cancer cervix }\end{array}$ & $36(29.5 \%)$ \\
\hline 8. & Screening interval should be & $18(14.8 \%)$ \\
\hline 9. & $\begin{array}{l}\text { Diagnostic Modalities other than } \\
\text { pap smear for detecting early } \\
\text { cancer }\end{array}$ & $76(62.3 \%)$ \\
\hline 10. & $\begin{array}{l}\text { Have you heard of HPV } \\
\text { vaccination? }\end{array}$ & $25(20.5 \%)$ \\
\hline
\end{tabular}

\section{DISCUSSION}

The purpose of this study was to evaluate knowledge regarding cervical cancer among primary healthcare workers in Shimla because identification of strengths and weaknesses in healthcare workers' knowledge may be crucial in targeted information campaigns.

The mean knowledge percent of the population was $55.9 \pm 16.4$ which means the overall knowledge of the population was moderate about cervical cancers. This is at par with the findings of Alali A who reported fair to good knowledge in his study. ${ }^{8}$ The mean knowledge was slightly higher among females though not statistically significant.

The mean knowledge was highest in the age group of 21$30 \mathrm{yrs}$ and it was lowest for the age group of 51-60 yrs. This may be because elderly age group have either lower educational qualification or joined their services long back and there was no reinforcement of knowledge about cervical cancers to the health workers. So, there should be continuous education programs to update the knowledge of primary health care workers about the cervical cancers.

Cervical cancer is most common cancers in females in India was reported correctly by $75 \%$ of the subjects which is higher than $62 \%$ as reported by Alali A. ${ }^{8} 44.3 \%$ of the subjects had correct knowledge about all the risk factors of cervical cancers which is at par with $46.4 \%$ as reported by Ertem $\mathrm{G}$ and higher than $36 \%$ as was reported by Catherine $M$ Kress. ${ }^{9,10}$ In present study, very low levels of knowledge on individual risk factors were 
reported as compared to findings by Tessaro and Herman [smoking (57.7\%), early age at first sexual intercourse $(90.6 \%)$, multiple sexual partners $(95.9 \%)$, history of sexually transmitted disease $(92.4 \%)]$ and by Ertem $G$ [smoking $(69.1 \%)$, early marriage age $(72.2 \%)$,multiple sexual partners $(81.4 \% \%)$, history of sexually transmitted disease $(87.6 \%)] .^{9,11}$

In present study, the association of HPV with cervical cancer was reported by $11.5 \%$ which is less than $23.4 \%$ reported by Shashank et al, $54 \%$ as reported by Singh E and $90 \%$ as reported by Alali A. ${ }^{8,12,13}$ Only $14.8 \%$ were aware of HPV vaccination which is at par with $18 \%$ as reported by Kress CM. ${ }^{10}$ So, a clear understanding of the link between HPV infection and cervical cancer, as well as an awareness about a vaccine against HPV were low among this population. As HPV testing and vaccination become available in Public sector in India, uptake is likely to be strongly influenced by information received from these health care providers. Therefore, increasing such awareness among this group of providers will be critical to the success of any public health initiatives. Currently HPV vaccines are only beginning to be available and that too only in the private sector in India.

Present study shows that $91 \%$ are aware of pap smear test which is lower than as reported by Singh E and one from Turkey by Ertem $G$ where almost all respondents had heard about the Pap smear. ${ }^{9,13}$ In those two studies only one-half of the subjects knew that it can detect both cancerous and precancerous lesions of cervical cancer where as in our study, $84.4 \%$ reported this. The rest believed that it is to detect existing cancer and required to be done in symptomatic cases only.

Another important finding is that $70 \%$ of the participants, were not aware of the eligibility criteria for screening interval. A study by Alali A reported that $90 \%$ of their population was not aware of who should be screened for cervical cancer and at what interval. ${ }^{8}$ On the contrary a study by Nganwai et al in thialand had very high proportion of population aware of screening eligibility and screening interval. ${ }^{14}$ This could be attributed to the training they have attended.

In present study, $62 \%$ of the subjects, could identify Visual inspection with lugols iodine (VIL), Visual inspection with acetic acid (VIA) and Colposcopy as various other diagnostic modalities for cervical cancer. VIL was reported by $9.8 \%$ in our study and by $6.8 \%$ by Singh E. ${ }^{13}$ Colposcopy was reported by $15 \%$ of subjects in our study and $19.6 \%$ by Singh E. ${ }^{13}$

The strength of the present study is that it is the first to assess knowledge regarding cervical cancer among female healthcare worker where incidence of cervical cancer is high and provide useful pointers for planning continuing education for healthcare workers. ${ }^{3}$ On the other hand, the study has some limitations. Firstly,the questionnaires were self-administrated; many of those distributed were not returned. One could therefore expect those who were less confident to have chosen not to answer and this study is based on a self-reported measure that especially may affect reporting.

From the present study, it can be concluded that this study has shown that half of the population had moderate overall knowledge about cervical cancers, but the knowledge about risk factors and screening eligibility and screening interval was inadequate. And however, there are no significant differences between knowledge about cervical cancer risk factors or symptoms and screening methods regarding gender, age, marital status, years of experience. It is hereby recommended that Continuing education programs for health care workers should be conducted at the hospital level to spread knowledge about cervical cancer risk factors, screening intervals, screening eligibility and methods of prevention so that they can play a vital role in the prevention of cervical cancer especially in a country like India where where 70 percent of population lives in rural areas. Healthcare workers should be trained to encourage screening as was also reported by them.

\section{Funding: No funding sources Conflict of interest: None declared Ethical approval: Not required}

\section{REFERENCES}

1. WHO/ICO. Information Centre on HPV and Cervical Cancer: HPV and ervical cancer in the 2007 report. Vaccine. 2007;25(Suppl 3):C1-230.

2. Government of India - World Health Organization Collaboration Programme 2004-2005. Guidelines for cervical cancer screening programme;2006.

3. Annual Reports. Himachal Pradesh: Regional Cancer Centre; 1998-2008:116-418.

4. World Health Organization. Cervical cancer screening in developing countries. Report of a WHO consultation. Geneva, WHO Press;2002.

5. Mahlck G, Jonsson H, Lenner P. Pap smear screening and changes in cervical cancer mortality in Sweden. Int J Gynecol Obstet. 1994;44(3):267-272.

6. Elovainio L, Nieminen P, Miller B. Impact of cancer screening on women's health. Int J Gynecol Obstet. 1997;58(1):137-147.

7. New Delhi: 2012. Available at http://www.districtdemographicstat.com/himachal/sh imla/index.aspx. [Last cited on 2013 Aug 17]. District Level Demographics Statistical Information 2012 [monograph on the internet]

8. Alali A, Salem M, Elmahdi H, Alkubaisi N, Alwahedi Z, Taher M. Knowledge, attitudes and practices regarding cervical cancer screening among Female health care workers in primary healthcare in Qatar. Middle East J Fam Medic. 2016;14(8):2-15.

9. Ertem G. Awareness of cervical cancer risk factors and screening behaviour among nurses in a rural 
region of Turkey. Asian Pac J Cancer Preven. 2009;10:735-8.

10. Kress CM, Sharling L, Owen-Smith AA, Desalegn D, Blumberg HM, Goedken J. Knowledge, attitudes, and practices regarding cervical cancer and screening among Ethiopian health care workers. Int J Women's Health. 2015;7:765.

11. Tessaro I, Herman C. Changes in Public Health Nurses' knowledge and perception of counseling and clinical skills for breast and cervical cancer control. Cancer Nursing. 2000;23:401-5.

12. Shekhar S, Sharma C, Thakur S, Raina N. Cervical cancer screening: knowledge, attitude and practices among nursing staff in a tertiary level teaching institution of rural India. Asian Pac J Cancer Prev. 2013;14(6):3641-5.

13. Singh E, Seth S, Rani V, Srivastava DK. Awareness of cervical cancer screening among nursing staff in a tertiary institution of rural India. J Gynecol Oncol. 2012;23(3):141-6.

14. Nganwai $P$, Truadpon $P$, Inpa $C$, Sangpetngam B, Mekjarasnapa M, Apirakarn $\mathrm{M}$ et al. Knowledge, attitudes and practices vis-a-vis cervical cancer among registered nurses at the Faculty of Medicine, KhonKaen University, Thailand. Asian Pac J Cancer Prev. 2008;9:15-8.

Cite this article as: Fotedar V, Fotedar S, Thakur P, Sharma M, Sharma A. Awareness about cervical cancers among health workers in Shimla district, Himachal Pradesh, India. Int J Reprod Contracept Obstet Gynecol 2017;6:4419-23. 